\begin{tabular}{|l}
\hline Feb unmul \\
\hline
\end{tabular}

\title{
Hubungan antara restaurant image, perceived value, customer satisfaction, dan behavioral intention
}

\author{
Larasati Ayu Sekarsari \\ Sekolah Tinggi Ilmu Ekonomi Perbanas, Surabaya. \\ Email: larasati.ayu@perbanas.ac.id
}

\begin{abstract}
Abstrak
Tujuan dari penelitian ini adalah untuk menjelaskan hubungan antara restaurant image, perceived value, customer satisfaction, dan behavioral intention pada casual dining restaurant di Kota Surabaya Jumlah sampel pada penelitian ini adalah sebanyak 200 responden yang dibagikan kepada konsumen yang pernah mengunjungi salah satu casual dining restaurant di Kota Surabaya. Penelitian ini menggunakan teknik purposive sampling dengan kriteria sebagai berikut: (1) pernah makan di salah satu casual dining restaurant di Kota Surabaya; dan (2) telah berusia minimal 17 tahun. Teknik analisis data dilakukan dengan menggunakan Partial Least Square (PLS) dengan SmartPLS 2.0. Hasil penelitian ini menunjukkan bahwa: (1) restaurant image secara signifikan memengaruhi perceived value; (2) restaurant image dan perceived value memiliki peran penitng dalam memengaruhi customer satisfaction; (3) hasil penelitian ini juga menunjukkan bahwa customer satisfaction memediasi secara signifikan hubungan antara restaurant image, perceived value dan behavioral intention.

Kata Kunci: restaurant image; perceived value; customer satisfaction behavioral intention; casual dining restaurant

\section{Hubungan antara restaurant image, perceived value, customer satisfaction, dan behavioral intention}

Abstract

The purpose of this research is to explain the relationships among restaurant image, perceived value, customer satisfaction, and behavioral intentions in casual dining restaurant in Surabaya. The total samples of 200 consumers who had dined at a casual dining restaurant in Surabaya as respondend on this study, collected using purposive sampling technique with the following criteria: (1) consumers who had dined at a casual dining restaurant in Surabaya; and (2) have at least 17 years. Data analysis techniques used in this study is Partial Least Square (PLS) with SmartPLS 2.0. The results of this study indicate that (1) overall restaurant image significantly influences perceived valuee; (2) overall restaurant image and perceived value had a significant role in influencing customer satisfaction; (3) the results of this study also showed that customer satisfaction is significantly mediate the relationship between restaurant image, perceived value, and behavioral intention.
\end{abstract}

Keywords: restaurant image; perceived value; customer satisfaction behavioral intention; casual dining restaurant 


\section{PENDAHULUAN}

Surabaya adalah kota perdagangan terbesar kedua setelah DKI Jakarta. Surabaya adalah kota perdagangan terbesar kedua setelah DKI Jakarta. Kota Surabaya merupakan Ibu Kota dari provinsi Jawa Timur. Luas Wilayahnya $\pm 33.306,30$ Ha dengan luas wilayah yang tersebut Surabaya merupakan kota padat penduduk, dengan jumlah penduduknya \pm 2.870 .500 jiwa. Surabaya merupakan pusat bisnis, perdagangan, industri, dan pendidikan di kawasan Indonesia Timur. Surabaya juga dikenal sebagai kota dagang internasional dan menjadi tumpuan dagang yang dilakukan melalui jalur maritim dan bertempat di Pelabuhan Perak sebagai dermaga transportasinya. Sebagai kota bisnis dan perdagangan sudah barang tentu, Surabaya menjadi destinasi banyak kalangan. Jumlah wisatawan yang berkunjung ke Surabaya baik untuk kepentingan bisnis maupun berwisata juga tidak bisa diremehkan. Salah satu bisnis yang memiliki pertumbuhan yang baik di Surabaya adalah bisnis restoran. Peraturan Walikota Surabaya Nomor 46 Tahun 2013 Tentang Rencana Kerja Pembangunan Daerah (RKPD) Kota Surabaya Tahun 2014 Sektor perdagangan hotel dan restoran (PHR) masih menjadi contributor utama pembentuk PDRB Kota Surabaya sebesar 43.29\%. Direktur Eksekutif dan Periset Konsumen The Nielsen Company, Catherine Eddy (2009), menyatakan bahwa masyarakat di negara - negara di Asia termasuk Indonesia menjadikan makan di luar sebagai salah satu cara untuk bersosialisasi. hal tersebut dibuktikan dengan hasil survey yang menunjukkan bahwa sebesar $44 \%$ dari masyarakat Indoensia suka makan di luar atau restoran (Nielsen Company, 2009). Kegiatan bersosialisasi atau berkumpul ini mayoritas dilakukan bersama keluarga, kerabat, dan pasangan (Nielsen Company, 2009). Bisnis restoran dan café saat ini mengalami pertumbuhan yang positif hingga 30 persen setiap tahunnya. Angka itu diketahui dari jumlah izin pendirian cafe dan restoran yang ada di Pemerintah Kota/Pemkot Surabaya (bisnissurabaya.com). Salah satu jenis restoran yang saat ini sedang menjamur adalah jenis casual dining restaurant ((Ha dan Jang (2010); Ponnam dan Balaji (2014); Jung, et.al (2015)). Restoran tipe dirancang untuk konsumen yang ingin menikmati makan di luar dengan suasana yang santai, menu makanan yang lebih sehat dan bervariasi, dengan layanan penuh (full table service) dari karyawan yang profesional.

Persaingan yang ketat dalam industri restoran saat ini menyebabkan pengusaha restoran kesulitan untuk menentukan mana konsumen yang loyal dan tidak. Konsumen cenderung selalu ingin mencoba menikmati menu baru yang ditawarkan, sehingga sanya sedikit dari konsumen yang sepenuhnya loyal pada satu restoran hingga restoran itu adalah satu-satunya yang mereka kunjungi. Fenomena tersebut mengharuskan para pengusaha di industri restoran untuk dapat menentukan sebuah differensiasi unik dan positioning yang jelas yang dapat membedakan restorannya dengan restoran yang lainnya. Pengusaha restoran juga harus membangun restaurant image agar menjadi ciri khas restorannya. Beberapa peneliti yang melakukan penelitian terhadap pengaruh restaurant image terhadap perilaku konsumen konsumen khususnya terhadap loyalitas konsumen di dalam sektor jasa. Hal tersebut didukung oleh Ryu, et.al (2008) yang menemukan bahwa restaurant image memiliki dampak yang signifikan pada nilai yang dirasakan konsumen (perceived value), kepuasan konsumen (customer satisfaction), dan behavioral intention. Lai et al. (2009) juga mengungkapkan bahwa citra perusahaan berpengaruh terhadap nilai yang dirasakan konsumen dan kepuasan konsumen, kedua kepuasan konsumen dan nilai yang dirasakan konsumen adalah prediktor signifikan yang memengaruhi loyalitas konsumen. Dengan demikian, konsumen percaya terhadap restoran yang memiliki citra yang baik mampu memberikan nilai dan kepuasan konsumen yang tinggi.

Berbeda dengan Ryu, et.al (2008), Ryu, Lee, dan Kim (2012) dalam penelitiannya yang dilakukan terhadap 310 konsumen 42 restoran Cina otentik yang terletak di negara Southeastern di Amerika Serikat menemukan bahwa restaurant image tidak berpengaruh signifikan terhadap customer satisfaction. Nugroho (2013) di dalam penelitiannya terhadap 160 konsumen restoran cepat saji KFC dan Hoka-Hoka Bento di Solo Square Surakarta juga menemukan bahwa restaurant image tidak berpengaruh signifikan terhadap customer satisfaction.

Customer satisfaction merupakan suatu hal yang sangat berharga dan demi untuk mempertahankan keberadaan pelanggan tersebut untuk tetap berjalannya suatu bisnis atau usaha. Banyak peneliti yang setuju bahwa konsumen yang puas terhadap barang dan jasa yang dikonsumsinya akan mempunyai kecenderungan untuk membeli ulang dari produsen yang sama. Behavioral intention timbul sebagai akibat dari kepuasan ini adalah keinginan untuk mengulang pengalaman yang baik dan menghindari pengalaman yang buruk (Solomon, 2002). Pernyataan 
tersebut di dukung oleh beberapa studi empiris yang mendukung hubungan positif antara customer satisfaction dan behavioral intention. Kivela, et.al (2000) menemukan bahwa dining satisfaction secara signifikan mempengaruhi post-dining behavioral intention. Kedua, Namkung dan Jang (2008) menemukan hubungan yang signifikan antara customer satisfaction dan behavioral intention pada mid-to-upscale restaurants. Ketiga, pada "fast-casual" restoran, Ryu, Han, dan Jang (2010) menemukan bahwa customer satisfaction secara positif berpengaruh terhadap behavioral intention.

Dengan adanya perbedaan hasil dari pengaruh antar variabel penelitian diatas, maka peneliti ingin melakukan penelitian kembali mengenai hubungan diantara variabel-variabel tersebut. Berdasarkan pemaparan dan dukungan dari teori yang telah dijelaskan sebelumnya, serta melihat pesatnya persaingan di bidang industri restoran di Indonesia khususnya kota Surabaya, maka peneliti tertarik melakukan penelitian untuk mengetahui bagaimana hubungan antara restaurant image, perceived value, customer satisfaction, dan behavioral intention pada casual dining restaurant di kota Surabaya.

\section{Kajian Literatur}

\section{Restaurant Image}

Riordan, Gatewood, dan Bill (1997) yang mengemukakan bahwa citra perusahaan merupakan suatu fungsi dan sinyal organisasi yang menentukan persepsi dan stakeholder berkaitan dengan aktivitas yang dilakukan perusahaan. Dengan kata lain, dapat dikatakan bahwa citra perusahaan adalah kesan-kesan yang muncul dalam pemikiran seseorang ketika mereka mendengar nama dari sebuah hotel, tempat, restoran, atau institusi bisnis lainnya. Keterkaitan konsumen pada suatu merek akan lebih kuat apabila dilandasi pada banyak pengalaman atau penampakkan untuk mengkomunikasikannya sehingga akan terbentuk citra merek (brand image). Citra merek yang baik akan mendorong untuk meningkatkan volume penjualan dan citra perusahaan. Citra merek dapat dianggap sebagai jenis asosiasi yang muncul di benak konsumen ketika mengingat sebuah merek tertentu. Asosiasi tersebut secara sederhana dapat muncul dalam bentuk pemikiran atau citra tertentu yang dikaitkan pada merek tertentu, sama halnya ketika kita berpikir mengenai orang lain.

Kotler dan Gary Armstrong (2012:225) menyatakan brand Image adalah himpunan keyakinan konsumen mengenai berbagai merek. Intinya brand images atau brand description, yakni diskripsi tentang asosiasi dan keyakinan konsumen terhadap merek tertentu. Dari sebuah produk dapat lahir sebuah brand jika produk itu menurut persepsi konsumen mempunyai keunggulan fungsi (functional brand), menimbulkan asosiasi dan citra yang diinginkan konsumen (image brand) dan membangkitkan pengalaman tertentu saat konsumen berinteraksi dengannya (experiental brand). Dalam industri restoran terdapat banyak faktor yang mempengaruhi behavioral intentions (perilaku konsumen) dari seorang konsumen restoran, dari banyak faktor tersebut diantaranya adalah restaurant image, perceived value, dan customer satisfaction (Ryu et al., 2008). Ryu et al. (2008) mengatakan bahwa seorang pengusaha restoran harus dapat membentuk citra yang khas dari restorannya agar dapat membedakan restorannya dengan restoran kompetitor dan juga dapat menyampaikan keunggulan dari restorannya kepada sasaran konsumen. Agar dapat bersaing dengan restoran kompetitor baru yang bermunculan, pengusaha restoran harus dapat membangun citra restoran agar menjadi ciri khas restorannya. Ryu et al. (2008) juga menemukan bahwa citra restoran memiliki pengaruh yang positif dan signifikan terhadap kepuasan konsumen. Selain itu, Yin dan Good (2007) dalam Hsu et al. (2009) juga menemukan bahwa citra toko/restoran memiliki pengaruh positif dan signifikan terhadap niat berperilaku.

\section{Perceived Value}

Menurut Kotler (2010: 34) "perceived value customer adalah selisih antara total customer value dan total customer cost. Total customer value (jumlah nilai bagi konsumen) adalah kumpulan manfaat yang diharapkan diperoleh konsumen dari produk atau jasa tertentu. Total customer cost (biaya konsumen total) adalah sekumpulan pengorbanan yang diperkirakan konsumen akan terjadi dalam mengevaluasi, memperoleh, dan menggunakan produk atau jasa tersebut. Beberapa studi empiris menemukan bahwa perceived value diterima sebagai prediktor yang memengaruhi customer satisfaction dan behavioral intention (McDougall dan Levesque, 2000; Ryu et.al., 2008; Ryu et.al., 2012). Chiou (2004) menunjukkan bahwa nilai yang dirasakan pelanggan adalah pendorong penting dari kepuasan pelanggan dalam bisnis penyedia layanan internet. McDougall dan Levesque (2000) 
melaporkan bahwa kualitas pelayanan dan nilai yang dirasakan pelanggan adalah dua variabel paling menonjol yang memengaruhi kepuasan pelanggan di empat industri jasa, yaitu restoran, auto layanan, penata rambut, dan dental care. Ryu et al. (2008) menemukan bahwa secara restaurant image pada quick-casual restaurant secara signifikan memengaruhi perceived value, dan quick-casual restaurant image dan perceived value secara signifikan mempengaruhi kepuasan pelanggan. Lebih lanjut, studi empiris ini juga menemukan bahwa restaurant imag, perceived value, dan customer satisfaction adalah prediktor signifikan yang memengaruhi behavioral intention pelanggan restoran.

\section{Customer Satisfaction}

Richard F. Gerson (2004:13-14), mendefinisikan "kepuasan pelanggan" adalah persepsi pelanggan bahwa harapannya telah terpenuhi atau terlampaui. Jika anda membeli suatu barang, anda berharap bahwa barang tersebut akan berfungsi dengan baik. Jika tidak, anda tentu kecewa. Di lain hal Robert (2005:13), mendefinisikan "kepuasan pelanggan" adalah dia yang membeli (meskipun tidak selalu dengan uang) dan menerima nilai dari barang dan jasa yang ditawarkan. Biasanya para pelanggan ini mempunyai pilihan. Apabila pelanggan tidak menyukai yang kita tawarkan atau cara kita menawarkannya, mereka bisa membeli di tempat lain untuk barang atau jasa yang sama. Pengamatan Kotler (2010:184), terhadap industri secara umum, hasilnya menunjukkan bahwa kemampuan suatu perusahaan dalam mempertahankan atau bahkan menarik pelanggan-pelanggannya sangat dipengaruhi oleh kemampuan perusahaan tersebut dalam menciptakan nilai melalui pelayanan yang memuaskan.

Sejumlah penelitian mengkonfirmasi hubungan positif dan langsung antara customer satisfaction dan behavioral intention, seperti pembelian kembali dan komunikasi word-of-mouth (Han dan Ryu, 2009; Kim et al, 2009; Kivela et al, 1999; Namkung dan Jang, 2007; Ryu et.al, 2008; Ryu, et.al 2012). Kivela et al. (1999) menemukan bahwa customer satisfaction secara signifikan dipengaruhi post-dining behavioral intention. Namkung dan Jang (2008) menegaskan hubungan positif antara customer satisfaction dan behavioral intention terhadap pelanggan restoran menengah ke atas. Semua temuan di atas mendukung hubungan yang signifikan antara customer satisfaction dan behavioral intention di industri restoran.

\section{Behavioral Intention}

Dining experience mempunyai pengaruh secara langsung terhadap behavioral intention pada casual dining restaurant di kota Surabaya (ditolak). Dining experience konsumen restoran terdiri dari pengetahuan atau pengamatan mereka mengenai atribut restoran yang diperoleh ketika mereka sedang mengunjungi dan bersantap di sebuah restoran. Pengalaman tersebut bisa bernilai positif maupun negatif tergantung penilaian subjektif mereka dari pengalaman saat ini dan pengalaman yang sudah mereka dapatkan sebelumnya. Melalui pengalaman sebelumnya, pelanggan dapat membandingkan dan memperoleh harapan tertentu untuk sebuah pelayanan di restoran. Pada saat pelanggan sedang makan di sebuah restoran dan mendapatkan pelayanan dari restoran tersebut, di sini mereka mampu menilai apakah dining experience tersebut bernilai positif (memuaskan) atau negatif (tidak memuaskan) (Jeong dan Jang, 2011). Secara konseptual, hal tersebut sangat dekat dengan pengukuran kualitas layananan yang dirasakan oleh pelanggan / pengunjung restoran terkait keunggulan pelayanan dari restoran tersebut (Jeong dan Jang, 2011).

Pemilik restoran bermaksud menciptakan behavioral intention ketika pembeli merasa terpuaskan. Behavioral intention dari pembeli sangatlah penting bagi perilaku pembelian berulang pada restoran yang sama. Kesuksesan sebuah restoran dapat ditandai dengan adanya perilaku pembelian ulang dari para pelanggannya dan kemampuan restoran untuk bertahan dalam menghadapi pesaing-pesaingnya. Sehingga, menciptakan behavioral intention dari konsumen menjadi fokus utama ketika kepuasan telah dirasakan konsumen. Pada pembelian awal di dalam sebuah restoran, konsumen dapat merasakan kesan positif maupun negatif terhadap kualitas makanan, kualitas layanan, dan lingkungan fisik yang dimiliki restoran. Setelah melakukan pembelian, konsumen dapat mengevaluasi hasil dari pembelian tersebut. Jika konsumen mendapatkan kepuasaan, maka behavioral intention dapat tercipta. Namun, jika konsumen tidak merasa puas, maka tidak dapat dihindari jika konsumen tersebut membuat keputusan untuk berpindah ke pesaing. Inilah mengapa tidak terdapat pengaruh signifikan secara langsung antara dining experience terhadap behavioral intention.

Hal tersebut di atas di dukung oleh penelitian yang dilakukan oleh Hutama dan Subagio (2014) di dalam penelitiannya yang berjudul Penelitian ini berjudul "Analisa Pengaruh Dining Experience 
Terhadap Behavioral Intention dengan Customer Satisfaction Sebagai Variabel Intervening (Studi Kasus: Domicile Kitchen and Lounge)". Mereka menemukan bahwa dining experience yang didalamnya terkandung food quality, service quality, dan physical environment tidak memiliki pengaruh secara langsung terhadap behavioral intention. Tetapi dining experience memiliki pengaruh tidak langsung terhadap behavioral intention melalui customer satisfaction.

\section{Casual Dining}

Menurut Mealey (2012), casual dining restaurant juga dikenal sebagai restoran gaya keluarga di Amerika Serikat. Sesuai namanya umumnya ramai dikunjungi pada saat jam makan malam. Restoran gaya kasual biasanya menawarkan harga yang lebih terjangkau. Restaurant yang melayani hampir semua jenis pengunjung. Orang-orang pergi di sini untuk dapat memiliki banyak pilihan makanan dan menikmati suasana santai. Restoran jenis ini adalah salah satu pasar paling luas di Amerika Serikat saat ini, yang notabene sebagai negara tujuan bagi para emigran. Restoran gaya kasual bisa hadir dalam berbagai tema menyesuaikan dengan sajian menu yang ditawarkan, biasanya ala Italia (Olive Garden) hingga seafood (Red Lobster) dan Mexican (Chilis). Restoran gaya kasual menawarkan full table service dan harga menunya lebih terjangkau.

\section{Hipotesis Penelitian}

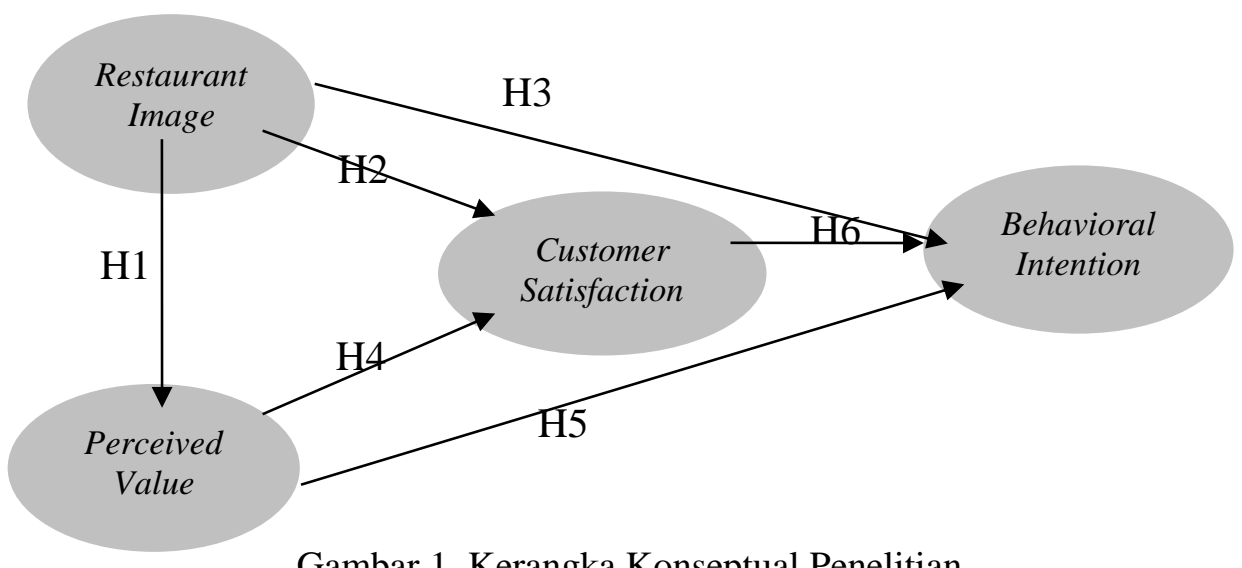

Hipotesis penelitian pada penelitian ini adalah sebagai berikut:

H1: $\quad$ Restaurant image mempunyai pengaruh secara langsung terhadap perceived value.

$\mathrm{H} 2$ : Restaurant image mempunyai pengaruh secara langsung terhadap customer satisfaction.

H3: Restaurant image mempunyai pengaruh tidak langsung terhadap behavioral intention melalui customer satisfaction.

H4: $\quad$ Perceived value mempunyai pengaruh secara langsung terhadap customer satisfaction.

H5: $\quad$ Perceived value mempunyai pengaruh tidak langsung terhadap behavioral intention melalui customer satisfaction.

H6: $\quad$ Customer satisfaction berpengaruh secara langsung terhadap behavioral intention.

\section{METODE}

Penelitian ini menggunakan pendekatan kuantitatif dengan jenis penelitian eksplanatori (explanatory research). Populasi pada penelitian ini adalah masyarakat yang pernah mengunjungi salah satu casual dining restaurant di Kota Surabaya. Adapun casual dining restaurant yang digunakan di dalam penelitian ini adalah casual dining restaurant yang memiliki jaringan nasional, antara lain Ikan Bakar Cianjur (IBC), My Kopi-O!, Bangi Kopitiam, Ta Wan, dan Rice Bowl. Total sampel sebesar 200 responden yang diambil dengan menggunakan metode purposive sampling dengan syarat responden adalah seseorang yang pernah makan di salah satu casual dining restaurant di Kota Surabaya dan responden telah berusia minimal 17 tahun. Teknik yang digunakan untuk mengumpulkan data dalam penelitian ini adalah dengan menggunakan kuesioner. Teknik pengukuran data yang digunakan dalam penelitian ini adalah dengan menggunakan skala Likert (Likert scale). Teknik analisis yang digunakan dalam penelitian ini adalah dengan menggunakan metode analisis 
deskriptif dan analisis inferensial. Keseluruhan tahap analisis data dilakukan dengan menggunakan bantuan program linieritas SPSS (Statistical Package for the Social Science) for Windows versi 18.0, dan Smart Modelling Partial Least Squares versi 2.0.

\section{HASIL DAN PEMBAHASAN}

Responden dalam penelitian ini adalah konsumen yang pernah mengunjungi salah satu casual dining restaurant di kota Surabaya, yaitu Ikan Bakar Cianjur (IBC), My Kopi-O, Bangi Kopitiam, Ta Wan, dan Rice Bowl dengan jumlah responden sebesar 200 orang. Analisis deskriptif terhadap 200 responden ini nampak bahwa jumlah responden perempuan lebih banyak dibandingkan laki - laki, yaitu 114 orang (57.0\%). Mayoritas rentang usia responden adalah 26-35 tahun sejumlah 85 orang $(42,5 \%)$, sehingga dapat disimpulkan bahwa responden pada penelitian ini berada dalam kategori usia produktif dan memasuki usia masa dewasa awal. Tingkat pendidikan responden mayoritas adalah sarjana (strata satu), sejumlah 93 orang (46.5\%), artinya para pengunjung casual dining restaurant pada penelitian ini termasuk kategori responden yang berpendidikan tinggi. Mayoritas pekerjaan responden pada penelitian ini adalah karyawan dari berbagai instansi swasta, berjumlah 65 orang (32.5\%). Selain itu, pelanggan yang mengunjungi casual dining restaurant didominasi oleh kelompok yang memiliki pendapatan/uang saku per-bulan lebih dari Rp 5.000.000,- yakni sejumlah 93 orang (46.5\%). Mayoritas responden memiliki frekuensi kunjungan ke casual dining restaurant sebanyak 1-2 kali dalam 1 bulan dengan persentase sebesar $81.5 \%$ (163 orang) dan memilih Ikan Bakar Cianjur sebagai tempat untuk bersantap dengan presentase $39.0 \%$.

Tabel 1. Frekuensi Persentase Karakteristik Responden

\begin{tabular}{|c|c|c|}
\hline Keterangan & Frekuensi & Persentase \\
\hline \multicolumn{3}{|l|}{ Jenis Kelamin } \\
\hline Laki - Laki & 86 & $43.0 \%$ \\
\hline Perempuan & 114 & $57.0 \%$ \\
\hline \multicolumn{3}{|l|}{ Usia } \\
\hline $17-25$ & 16 & $8.0 \%$ \\
\hline $26-35$ & 85 & $42.5 \%$ \\
\hline $36-45$ & 65 & $32.5 \%$ \\
\hline $46-55$ & 17 & $8.5 \%$ \\
\hline $56-65$ & 13 & $6.5 \%$ \\
\hline$>65$ & 4 & $2.0 \%$ \\
\hline \multicolumn{3}{|l|}{ Pendidikan Terakhir } \\
\hline SMA/MA/MK & 17 & $8.5 \%$ \\
\hline Diploma (D3) & 21 & $10.5 \%$ \\
\hline Sarjana (S1) & 93 & $46.5 \%$ \\
\hline Magister (S2) & 54 & $27 \%$ \\
\hline Doktor (S3) & 13 & $6.5 \%$ \\
\hline Lain - lain & 2 & $1.0 \%$ \\
\hline \multicolumn{3}{|l|}{ Pekerjaan } \\
\hline Pegawai Negeri Sipil (PNS) & 6 & $3.0 \%$ \\
\hline Profesional & 47 & $23.5 \%$ \\
\hline Pegawai Swasta & 65 & $32.5 \%$ \\
\hline Wiraswasta & 32 & $16.0 \%$ \\
\hline Pensiunan & 10 & $5.0 \%$ \\
\hline Ibu Rumah Tangga & 8 & $4.0 \%$ \\
\hline Pelajar/Mahasiswa & 18 & $9.0 \%$ \\
\hline TNI/Polri & 10 & $5.0 \%$ \\
\hline Lain - lain & 4 & $2.0 \%$ \\
\hline \multicolumn{3}{|l|}{ Pendapatan Per Bulan } \\
\hline Rp 1.000.000,00 - Rp. 1.999.999,00 & 9 & $4.5 \%$ \\
\hline Rp 2.000.000,00 - Rp. 2.999.999,00 & 11 & $5.5 \%$ \\
\hline Rp 3.000.000,00 - Rp. 3.999.999,00 & 25 & $12.5 \%$ \\
\hline Rp 4.000.000,00 - Rp. 5.000.000,00 & 62 & $31.0 \%$ \\
\hline$>$ Rp 5.000.000,00 & 93 & $46.5 \%$ \\
\hline Frekuensi Kunjungan (Per Bulan) & & \\
\hline
\end{tabular}




\begin{tabular}{|c|c|c|}
\hline Keterangan & Frekuensi & Persentase \\
\hline $1-2$ & 163 & $81.5 \%$ \\
\hline $3-4$ & 37 & $18.5 \%$ \\
\hline \multicolumn{3}{|l|}{ Casual Dining Restaurant } \\
\hline Ikan Bakar Cianjur (IBC) & 78 & $39.0 \%$ \\
\hline My Kopi-O & 32 & $16.0 \%$ \\
\hline Bangi Kopitiam & 28 & $14.0 \%$ \\
\hline Ta Wan & 42 & $21.0 \%$ \\
\hline Rice Bowl & 20 & $10 \%$ \\
\hline
\end{tabular}

Sumber: Lampiran Output SPSS, data diolah (2018)

Analisis data penelitian menggunakan pendekatan Structural Equation Modeling (SEM) dengan menggunakan metode analisis Partial Least Square (PLS) dan dengan bantuan program aplikasi Smart Modelling Partial Least Squares versi 2.0. karena penelitian ini menggunakan variabel mediasi. Adapun tahapan dari analisis SEM, adalah Outer Model dan Inner Model, sebagai berikut:

\section{Evaluasi Outer Model}

\section{Convergent Validity}

Convergent validity dari measurement model dengan indikator refleksif dapat dilihat dari korelasi score item dengan score variabelnya. Indikator dinyatakan valid apabila nilai korelasi (loading factor) pada convergent validity di atas 0,5 (Ghozali, 2011:29). Berikut adalah gambar measurement model:

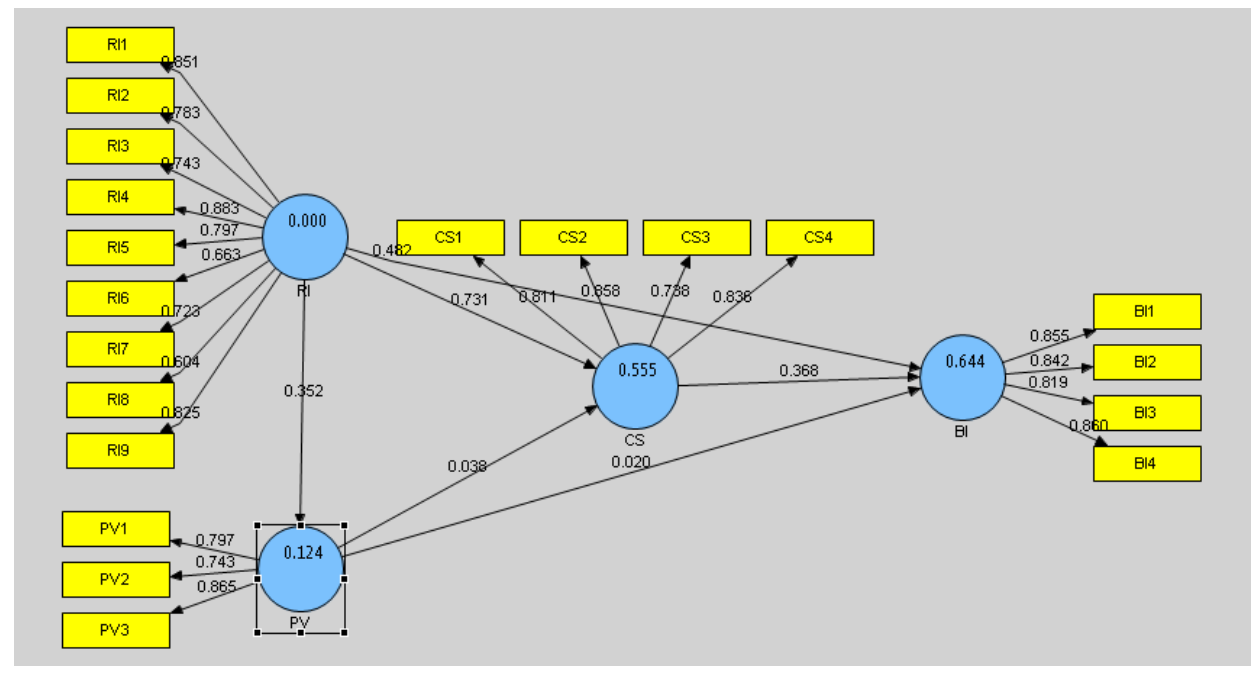

Gambar 2. Measurement Outer Model

Sumber: Lampiran Output SmartPLS, data diolah (2018)

Berdasarkan Gambar 2 di atas, maka nilai loading factor dari masing-masing indikator variabel laten restaurant image $\left(X_{1}\right)$, perceived value $\left(Y_{1}\right)$, customer satisfaction $\left(Y_{2}\right)$, dan behavioral intention $(Z)$ telah memenuhi persyaratan, atau dapat dikatakan indikatornya mewakili atau membentuk variabel laten tersebut, karena convergent validity (loading factor) diatas 0,5. Dan berdasarkan Gambar 1. di atas, maka nilai loading factor dari masing-masing item dapat dilihat pada Tabel 1 sebagai berikut:

Tabel 2. Outer Loadings

\begin{tabular}{ccccc}
\hline Variabel & Item & Loading Factor & Cut Off & Keterangan \\
\hline & X1.1 & 0.851 & 0.5 & Valid \\
Restaurant Image $(X)$ & X1.2 & 0.783 & 0.5 & Valid \\
& X1.3 & 0.743 & 0.5 & Valid \\
& X1.4 & 0.883 & 0.5 & Valid \\
& X1.5 & 0.797 & 0.5 & Valid \\
& X1.6 & 0.663 & 0.5 & Valid \\
& X1.7 & 0.723 & 0.5 & Valid
\end{tabular}




\begin{tabular}{ccccc} 
& X1.8 & 0.604 & 0.5 & Valid \\
& X1.9 & 0.825 & 0.5 & Valid \\
\hline \multirow{3}{*}{ Perceived Value $\left(\boldsymbol{Y}_{1}\right)$} & Y 1.1 & 0.797 & 0.5 & Valid \\
& Y1.2 & 0.743 & 0.5 & Valid \\
& Y1.3 & 0.865 & 0.5 & Valid \\
\hline \multirow{3}{*}{ Customer Satisfaction $\left(\boldsymbol{Y}_{2}\right)$} & Y 2.1 & 0.811 & 0.5 & Valid \\
& Y2.2 & 0.858 & 0.5 & Valid \\
& Y2.3 & 0.738 & 0.5 & Valid \\
& Y2.4 & 0.836 & 0.5 & Valid \\
\hline \multirow{3}{*}{ Behavioral Intention $(Z)$} & Z.1 & 0.855 & 0.5 & Valid \\
& $\mathrm{Z} .2$ & 0.842 & 0.5 & Valid \\
& $\mathrm{Z} .3$ & 0.819 & 0.5 & Valid \\
& $\mathrm{Z} .4$ & 0.860 & 0.5 & Valid \\
\hline
\end{tabular}

Sumber: Data primer diolah, 2018

Berdasarkan Tabel 2 di atas, dapat diketahui bahwa nilai outer loadings lebih besar dari 0.50 , berarti sembilan indikator dari variabel restaurant image $(\mathrm{X})$ mempunyai convergent validity yang baik. Perceived value (Y1) dibentuk dari tiga indikator (offered good value for the price, overall value of dining, dining experiences was worth the money) yang masing-masing memiliki nilai outer loadings lebih besar dari 0.50 , berarti indikator-indikator dari variabel perceived value (Y1) mempunyai convergent validity yang baik. Customer satisfaction (Y2) dibentuk dari empat indikator yang masingmasing memiliki nilai outer loadings lebih besar dari 0.50 , berarti indikator-indikator dari variabel customer satisfaction (Y2) mempunyai convergent validity yang baik. Behavioral intention (Z) dibentuk dari empat indikator (revisit intention, purchase more or revisit more often, positive word of mouth, recommendation) yang masing-masing memiliki nilai outer loadings lebih besar dari 0.50 , berarti indikator-indikator dari variabel behavioral intention $(Z)$ juga mempunyai convergent validity yang baik.

\section{Discriminant Validity}

Suatu variabel dinyatakan memenuhi discriminant validity apabila memiliki nilai AVE $>0,50$. Berikut hasil uji Average Variance Extracted (AVE):

Tabel 3. Hasil Average Variance Extracted (AVE)

\begin{tabular}{lcccc}
\hline \multicolumn{1}{c}{ Variabel } & AVE & Communality & Cut Off & Keterengan \\
\hline Restaurant Image $\left(X_{1}\right)$ & 0.590 & 0.590 & 0.5 & Valid \\
Perceived Value $\left(Y_{1}\right)$ & 0.645 & 0.645 & 0.5 & Valid \\
Customer Satisfaction $\left(Y_{2}\right)$ & 0.659 & 0.659 & 0.5 & Valid \\
Behavioral Intention $(Z)$ & 0.712 & 0.712 & 0.5 & Valid \\
\hline
\end{tabular}

Sumber: Data primer diolah, 2018

Pada Tabel 3. menunjukkan bahwa semua variabel yaitu restaurant image (X1), perceived value (Y1), customer satisfaction (Y2), dan behavioral intention (Z) memiliki nilai AVE dan Communality yang lebih besar dari 0.5. Hal itu menunjukkan bahwa keseluruhan variabel telah memenuhi kriteria discriminant validity. Sehingga dapat dinyatakan bahwa item-item pertanyaan telah valid dalam mengukur variabelnya.

\section{Composite Reliability}

Perhitungan yang dapat digunakan untuk menguji reliabilitas konstruk adalah cronbach alpha dan composite reliability. Kriteria pengujian menyatakan bahwa apabila composite reliability bernilai lebih besar dari 0.7 dan cronbach alpha bernilai lebih besar dari 0.6 maka konstruk tersebut dinyatakan reliabel. Berikut adalah hasil output composite reliability dari PLS: 
Tabel 4. Hasil Cronbach Alpha dan Composite Reliability

\begin{tabular}{lccc}
\hline \multicolumn{1}{c}{ Variabel } & Composite Reliability Cronbachs Alpha Keterangan \\
\hline Restaurant Image $\left(X_{1}\right)$ & 0.927578 & 0.911184 & Reliabel \\
Perceived Value $\left(Y_{1}\right)$ & 0.844200 & 0.730806 & Reliabel \\
Customer Satisfaction $\left(Y_{2}\right)$ & 0.885290 & 0.826696 & Reliabel \\
\hline Behavioral Intention $(Z)$ & 0.908246 & 0.866038 & Reliabel \\
\hline
\end{tabular}

Sumber: Data primer diolah, 2018

\section{Evaluasi Inner Model}

Model struktural (inner model) dalam PLS dievaluasi dengan menggunakan R2 untuk konstruk dependen dan nilai Path Coefficients atau $t$-value ( $t$-statistic) untuk uji signifikansi antar konstruk. Semakin tinggi nilai R2 berarti semakin baik prediksi dari model yang diajukan. Ghozali (2011:68) menjelaskan skor Path Coefficients atau inner model yang ditunjukkan nilai $t$-statistic harus di atas 1,96 untuk pengujian hipotesis pada alpha (tingkat kesalahan penelitian) sebesar 5\%.

\section{Goodness of Fit Model}

Goodness of fit Model digunakan untuk mengetahui kontribusi variabel eksogen terhadap variabel endogen. Goodness of fit Model dalam analisis PLS dilakukan dengan menggunakan Q-Square predictive relevance $\left(Q^{2}\right)$. Adapun hasil Goodness of fit Model yang telah diringkas dalam Tabel 5 berikut ini:

Tabel 5. Hasil R-Square

\begin{tabular}{lc}
\hline \multicolumn{1}{c}{ Variabel } & $\boldsymbol{R}^{2}$ \\
\hline Perceived Value $\left(Y_{1}\right)$ & 0.124 \\
Customer Satisfaction $\left(Y_{2}\right)$ & 0.555 \\
Behavioral Intention $(Z)$ & 0.644 \\
\hline Total Kontribusi & $\mathbf{0 . 8 6 1}$ \\
\hline Sumber: Data primer diolah, 2018 &
\end{tabular}

Pada Tabel 5 terdapat total kontribusi, hasil tersebut didapat dengan perhitungan sebagai berikut.

$$
\begin{aligned}
\mathrm{Q}^{2} & =1-\left(1-\mathrm{R}_{1}{ }^{2}\right)\left(1-\mathrm{R}_{2}{ }^{2}\right)\left(1-\mathrm{R}_{2}{ }^{3}\right) \\
& =1-(1-0.124)(1-0.555)(1-0.644) \\
& =1-0.13877592 \\
& =\mathbf{0 . 8 6 1 2 2 4 0 8}
\end{aligned}
$$

Nilai $R_{m}^{2}$ sebesar 0.861 mengartikan bahwa keragaman data yang dapat dijelaskan oleh model tersebut adalah sebesar $86.1 \%$ atau dengan kata lain informasi yang terkandung dalam data $86.1 \%$ dapat dijelaskan oleh model tersebut. Sedangkan sisanya yaitu $13.9 \%$ dijelaskan oleh variabel lain diluar model yang digunakan dalam penelitian ini.

\section{Uji Hipotesis}

\section{Pengujian Pengaruh Langsung}

Dari tingkat signifikansi antar indikator, tahapan selanjutnya adalah mengetahui signifikansi pengaruh hubungan antar variabel. Tingkat signifikansi didapatkan dengan membandingkan t-hitung dengan nilai t-tabel. Jika nilai t-hitung lebih besar dati t-tabel maka hubungan antar variabel tersebut signifikan. Jumlah data sebesar 200, maka nilai t-tabel $(\alpha=5 \%)$ sebesar 1.96. hasil hubungan antar variabel disajikan pada Tabel 6.

Tabel 6. Hasil Pengujian Hipotesis Pengaruh Langsung

\begin{tabular}{clcccc}
\hline Hipotesis & \multicolumn{1}{c}{ Hubungan } & $\begin{array}{c}\text { Path } \\
\text { Coefficients }\end{array}$ & t-hitung & $\begin{array}{c}\text { t- } \\
\text { tabel }\end{array}$ & Keterangan \\
\hline H1 & Restaurant Image $\rightarrow$ Perceived Value & 0.352487 & 4.071724 & 1.96 & Signifikan \\
\hline H2 & Restaurant Image $\rightarrow$ Customer Satisfaction & 0.743919 & 15.678152 & 1.96 & Signifikan \\
\hline H4 & Perceived Value $\rightarrow$ Customer Satisfaction $\rightarrow$ & 0.757724 & 14.366358 & 1.96 & Signifikan \\
\hline H6 & Customer Satisfaction $\rightarrow$ Behavioral Intention & 0.368400 & 4.086498 & 1.96 & Signifikan \\
\hline
\end{tabular}

Sumber: Data primer diolah, 2018

Hasil pengujian hipotesis pengaruh langsung pada penelitian ini dapat dilihat pada Tabel 6 . Hasil dari Tabel 6 menunjukkan bahwa : (H1) restaurant image memiliki pengaruh yang signifikan 
terhadap perceived value, hal ini dapat dilihat dari nilai t-hitung sebesar 4.071 yang lebih besar dari nilai t-tabel yang sebesar 1.96; $(\mathrm{H} 2)$ restaurant image memiliki pengaruh yang signifikan terhadap customer satisfaction, hal ini dapat dilihat dari nilai t-hitung sebesar 15.678 yang lebih besar dari nilai t-tabel yang sebesar 1.96; (H4) perceived value memiliki pengaruh yang signifikan terhadap customer satisfaction, hal ini dapat dilihat dari nilai t-hitung sebesar 14.366 yang lebih kecil dari nilai t-tabel yang sebesar 1.96; (H6) customer satisfaction memiliki pengaruh yang signifikan terhadap behavioral intention, hal ini dapat dilihat dari nilai t-hitung sebesar 4.086 yang lebih besar dari nilai t-tabel yang sebesar 1.96 .

Tabel 7. Hasil Pengujian Hipotesis Pengaruh Tidak Langsung

\begin{tabular}{|c|c|c|c|c|c|}
\hline \multirow[t]{2}{*}{ Hipotesis } & \multirow{2}{*}{$\begin{array}{l}\text { Variabel } \\
\text { Eksogen }\end{array}$} & \multirow{2}{*}{$\begin{array}{l}\text { Variabel } \\
\text { Endogen }\end{array}$} & \multirow[t]{2}{*}{ Melalui } & \multicolumn{2}{|c|}{ Pengaruh Kausal } \\
\hline & & & & Langsung & Tidak Langsung \\
\hline $\mathrm{H} 3$ & $\begin{array}{c}\text { Restaurant } \\
\text { Image }\end{array}$ & $\begin{array}{c}\text { Behavioral } \\
\text { Intention }\end{array}$ & $\begin{array}{c}\text { Customer } \\
\text { Satisfaction }\end{array}$ & 0.215453 & $\begin{array}{c}0.743919 \times 0.368400= \\
\mathbf{0 . 2 7 4 0 6 0}\end{array}$ \\
\hline $\mathrm{H} 5$ & $\begin{array}{l}\text { Perceived } \\
\text { Value }\end{array}$ & $\begin{array}{l}\text { Behavioral } \\
\text { Intention }\end{array}$ & $\begin{array}{c}\text { Customer } \\
\text { Satisfaction }\end{array}$ & 0.236942 & $\begin{array}{c}0.757724 \times 0.368400= \\
\mathbf{0 . 2 7 9 1 4 6}\end{array}$ \\
\hline
\end{tabular}

Sumber: Data primer diolah, 2018

Restaurant image mempunyai pengaruh tidak langsung terhadap behavioral intention melalui customer satisfaction pada casual dining restaurant di kota Surabaya. Berdasarkan Tabel 7 dapat dijelaskan bahwa pengaruh tidak langsung restaurant image terhadap behavioral intention melalui customer satisfaction memiliki nilai koefisien sebesar 0.274060, sedangkan besarnya nilai koefisien pengaruh langsung restaurant image terhadap behavioral intention sebesar 0.215453. Hasil ini menunjukkan bahwa besarnya nilai koefisien pengaruh tidak langsung lebih besar dari pengaruh langsung, sehingga dapat diinterpretasikan bahwa variabel customer satisfaction dapat memediasi pengaruh restaurant image terhadap behavioral intention.

Perceived value mempunyai pengaruh tidak langsung terhadap behavioral intention melalui customer satisfaction pada casual dining restaurant di kota Surabaya. Berdasarkan Tabel 7 dapat dijelaskan bahwa pengaruh tidak langsung perceived value terhadap behavioral intention melalui customer satisfaction memiliki nilai koefisien sebesar 0.279146 , sedangkan besarnya nilai koefisien pengaruh langsung perceived value terhadap behavioral intention sebesar 0.236942. Hasil ini menunjukkan bahwa besarnya nilai koefisien pengaruh tidak langsung lebih besar dari pengaruh langsung, sehingga dapat diinterpretasikan bahwa variabel customer satisfaction dapat memediasi pengaruh perceived value terhadap behavioral intention.

\section{SIMPULAN}

Penelitian ini hanya dilakukan pada pelanggan di 5 casual dining restaurant di kota Surabaya. Pada penelitian yang akan datang dapat melakukan penelitian pada pelanggan di casual dining restaurant lain yang ada di kota Surabaya ataupun kota lainnya. Untuk memastikan validitas eksternal, dibutuhkan sampel yang lebih luas di seluruh geografi yang beragam yang dibutuhkan dalam penelitian masa depan.

Variabel yang digunakan dalam penelitian ini terbatas pada variabel dining experiences, customer satisfaction, restaurant image, dan behavioral intention. Untuk penelitian yang akan datang dapat ditambahkan variabel lain yang tidak diteliti dalam penelitian ini yang juga berpengaruh terhadap behavioral intention.

Karakteristik responden dalam penelitian ini terbatas pada jenis kelamin, frekuensi kunjungan ke casual dining restaurant dalam 1 bulan, usia, pekerjaan, pendidikan terakhir, dan pendapatan/uang saku per bulan. Untuk penelitian yang akan datang dapat ditambahkan karakteristik lain yang tidak diteliti dalam penelitian ini.

Pembahasan di dalam penelitian ini hanya tertuju pada bisnis restoran khususnya casual dining restaurant. Untuk penelitian yang akan datang penelitian dapat diterapkan pada industri/bisnis jasa lainnya seperti finansial, hospitality (perhotelan), retailing (ritel/ecer), online shopping, kiriman kilat, dan lainnya. 


\section{DAFTAR PUSTAKA}

Canny, I. U., (2014). Measuring The Mediating Role of Dining Experience Attributes on Customer Satisfaction and Its Impact on Behavioral Intentions Of Casual Dining Restaurant in Jakarta. International Journal of Innovation, Management and Technology, Vol. 5, No. 1, February 2014.

Chiou, J.S. (2004). The antecedents of consumers' loyalty toward internet service providers. Information and Management, Vol. 41 No. 6, pp. 685-95.

Engel. James.F.Roger. D.Black Well And Paul.W.Miniard. (1995).,Perilaku Konsumen.Jakarta.Bina Rupa Aksara.Hal. 3.

Gerson, Richard. F. (2004).Mengukur Kepuasan Pelanggan, PPM, Jakarta.

Ghozali, Imam. (2011). “Aplikasi Analisis Multivariate Dengan Program SPSS”. Semarang: Badan Penerbit Universitas Diponegoro.

Griffin, Jill. (2003). Customer Loyalty : Menumbuhkan Dan Mempertahankan Pelanggan. Jakarta, Airlangga

Ha, J., Jang, S.S. (2010). Effects of service quality and food quality: the moderating role of atmospherics in an ethnic restaurant segment. International Journal of Hospitality Management, Vol.29, No.3, pp 520-529.

Han, H. and Ryu, K. (2009). The roles of the physical environment, price perception, and customer satisfaction in determining customer loyalty in the restaurant industry. Journal of Hospitality and Tourism Research. Vol. 33 No. 4, pp. 487-51

Hsu, M. K., Huang, Y., and Swanson, S. (2009). Grocery store image, travel distance, satisfaction and behavioral intentions: Evidence from a Midwest college town. International Journal of Retail \& Distribution Management, Vol. 38, pp.115-32.

Hutama, Christanto Leoma dan Hartono Subagio. (2014). Analisa pengaruh dining experience terhadap behavioral intention dengan customer satisfaction sebagai variabel intervening (studi kasus : domicile kitchen and lounge). Jurnal Manajemen Pemasaran Petra, vol. 2, no. 1

Jeoung, EunHa and SooCheong Jang. (2011). Restaurant experiences triggering positive electronic word-of-mouth (eWOM) Motivations. International Journal of Hospitality Management, vol. 30, pp. 356-366.

Jung, Jae Man, Sandra Sydnor, Seul Ki Lee, and Barbara Almanza. (2015). A conflict of choice: How consumers choose where to go for dinner. International Journal of Hospitality Management, Vol. 45, pp. 88-98

Kim, W.G., Ng, C.Y.N. and Kim, Y.S. (2009). Influence of international DINESERV on customer satisfaction, return intention, and word-of-mouth. International Journal of Hospitality Management. Vol. 28 No. 1, pp. 10-17.

Kivela, J., Inbakaran, R. and Reece, J. (1999). Consumer research in the restaurant environment, part 1: A conceptual model of dining satisfaction and return patronage. International Journal of Contemporary Hospitality Management, vol. 11, No. 5, pp. 205-222.

Kivela, J., Inbakaran, R., Reece, J., (2000). Consumer research in the restaurant environment. Part 3: analysis, findings and conclusions. International Journal of Contemporary Hospitality Management. Vol.12, No.1, pp.13-30.

Kotler Philip, and Gary Amstrong. (2012). Principles Of Marketing.14 th Edition. New Jersey: Pearson Education, Inc.

Kotler, Philip. (2010). Manajemen Pemasaran, Edisi Milenimun, Benyamin Molan (Terjemahan), Prehalindo, Jakarta. 
Lai, F., Griffin, M. and Babin, B.J. (2009). How quality, value, image, and satisfaction create loyalty at a Chinese telecom, Journal of Business Research, Vol. 62 No. 10, pp. 980-6.

Namkung, Y., \& Jang, S. (2008). Does food quality really matter in restaurants? Its impact on customer satisfaction and behavioral intentions. Journal of Hospitality and Tourism Research, Vol. 31, No.3, pp. 387-409.

Oliver, Richard L., 1999, "Whence Consumer Loyalty", Journal of Marketing., Volume 63 Special Issue, pp. 33-44.

Riordan, Christine, Robert. D. Gatewood and Jodi Barnes Bill. (1997). Corporote Image: Employee Reaction and Implications for Managing Corporate Social Performance. Journal of Business Ethics, Vol. 16, pp. 401-412.

Robert Bacal. (2005). Performance Management. Dalam Sarwoto. 1983(Ed.), Definisi Motivasi. Jakarta: GM

Ruslan, Rosady. (1994). Praktik dan Solusi Public Relations dalam Situasi Krisis dan Pemulihan Citra, Jakarta: Ghalia Indonesia.

Ryu, K. and Han, H. (2010). Influence of the quality of food, service, and physical environment on customer satisfaction in quick-casual restaurants: moderating role of perceived price. Journal of Hospitality \& Tourism Research, Vol. 34 No. 3, pp. 310-29.

Ryu, Kisang, Heesup Han, and Tae-Hee Kim. (2008). The relationships among overall quick-casual restaurant image, perceived value, customer satisfaction, and behavioral intentions. International Journal of Hospitality Management, Vol. 27, pp. 459-469

Ryu, Kisang, Hye-Rin Lee, and Woo Gon Kim. (2012). The influence of the quality of the physical environment, food, and service on restaurant image, customer perceived value, customer satisfaction, and behavioral intentions. International Journal of Contemporary Hospitality Management, Vol. 24, No. 2, pp. 200-223.

Solomon, R. Michael. (2002). Consumer Behavior, Buying, Having, and Being. 8th. Edition. New Jersey: Prentice Hall.

Tang, W. (2007). Impact of Corporate image and Corporate Reputation on Customer Loyalty: A Review. Management Science and Engineering. 1(2): 57-62.

Tjiptono, Fandy. (2008). Pemasaran Strategik. Penerbit Andi. Yogyakarta.

Yang, Z. dan Peterson, R.T., (2004), "Customer Perceived Value, Satisfaction, and Loyalty: The Role of Switching Costs", Psychology \& Marketing Journal, Vol. 21(10), October, p.99-822.

Zeithaml, Valarie A. and Bitner, Mary Jo. (2003). Service Marketing. McGraw Hill Inc, Int'l Edition, New York. 